taken the first steps towards building new synchrotron radiation facilities. The French Centre National de la Recherche Scientifique (CNRS) and the Commissariat à l'Energie Atomique (CEA) were this week scheduled to approve a FF24-million (US\$4.7-million) detailed design phase for a 2.15-GeV machine, called Soleil.

This machine is intended to replace France's existing LURE facilities $(800 \mathrm{MeV}$ and $1.85 \mathrm{GeV}$ ) at Orsay, near Paris. The Swiss government last month also approved a SFr1.8-million (US\$1.46 million) study phase for a similar machine, the $2.1-\mathrm{GeV}$ Swiss Light Source (SLS).

All three countries are collaborating closely on plans to build third-generation synchrotron sources, in a bid to make savings by carrying out joint design work, and planning each machine to be as complementary as possible to the needs of user communities in all three countries, according to Catherine Cesarsky, the head of 'sciences of matter' at CEA.

One idea that has been floated would be to replace Diamond and Soleil with a shared SRS, built jointly by the United Kingdom and France. But Jacques Sevin, director of strategy and programmes at CNRS, argues that the demand for synchrotron radiation in each country is sufficient to justify building two machines, and points out that Diamond and Soleil would also be complementary, given that they would operate at different energy levels.

Newport argues that the task of building a single machine that could accommodate 6,000 users would reduce the potential for cost savings. But Cesarsky says that the proposal to build a single machine cannot be completely ruled out.

Declan Butler \& David Dickson

\section{ESO membership}

track", he said "the opportunity was now as contracts are soon to close out" and branded the decision as "abysmal".

Mould points out that a government survey showed astrophysics as Australia's "top science in international impact". He adds: "First-rate facilities have underpinned this performance. If Australian governments treat their best scientists in this way, what are the prospects for science as a whole?"

According to Mould, the astronomers are now "regrouping" for a further campaign. He says that he is disappointed that the minister would not allow negotiations to proceed, which Mould believes "would have led to a deal for phasing the payments to match the government's needs and constraints or an honourable disengagement".

Riccardo Giacconi, director general of the ESO, said that the Australian government's decision was to be "regretted". But, he is keen to keep lines of communication open between European and Australian scientists and engineers." Peter Pockley

\title{
Argonne sees bright future from new photon source
}

Washington. The long-term future of the Argonne National Laboratory near Chicago was effectively secured last week with the inauguration of the Advanced Photon Source (APS), providing US scientists with a new and immensely powerful X-ray source.

But many fear that the APS will prove to be the last large machine built according to past criteria of scientific need - and regional 'fairness' - and that raising funding for similar facilities in the future will prove to be considerably harder.

The \$1-billion, 7-GeV APS is comparable in specification to the European Synchrotron Radiation Facility (ESRF), which opened in France 18 months ago (see Nature 371, 469; 1994), and the Super Photon Ring now under construction in Japan.

In addition to the high electron-beam energies needed to produce 'hard' X-rays, this new generation of radiation synchrotrons is purpose-built to incorporate insertion devices, known as 'wigglers', which produce coherent X-ray beams of far greater brilliance than those from older synchrotrons.

About 2,000 scientists are expected to use the 35 beam lines that will collect X-rays from the APS synchrotron. Most of them will be materials scientists, chemists and structural biologists. But other disciplines will also make use of the penetrating X-rays to study molecular and crystal structures.

The arrival of the facility will "provide tremendous intellectual excitement" at Argonne, says Alan Schriesheim, the laboratory director, who is due to retire this summer after 12 years in charge.

The US Department of Energy has so far spent $\$ 800$ million to build the facility and to begin operation, and will budget around $\$ 70$ million a year for its operation. It has also attracted $\$ 160$ million from universities, other agencies and industries to equip the beam lines themselves, with about a quarter of that coming from the private sector.

Fifteen Collaborative Access Teams (CATs) have been set up to run the different beam lines. Most are consortia of industry, government laboratories and universities. But one - the Industrial Macromolecular Crystallography Association CAT - is a consortium of eleven pharmaceutical companies that will use its beam for drug design.

The APS is designed to complement the Advanced Light Source at the Lawrence Berkeley Laboratory in California, which opened in 1993 and supplies lower energy, 'soft' X-rays. In the view of some congressional staff, these machines ought to replace the existing radiation synchrotrons at the Brookhaven National Laboratory (BNL) on Long Island, New York, and at the Stanford

\section{Linear Accelerator Center in California.}

But the scientific reputation of these centres, together with their potential for industrial application - particularly in materials technology and drug design - has strengthened their case for funding. Even as APS comes on line, the National Synchrotron Light Source (NSLS) at BNL has had its operating budget increased this year to $\$ 26$ million, and is full to capacity, according to Michael Hart, its chairman.

Hart argues that most scientists do not need the extra brightness, the main asset of the APS. He points out that the NSLS is easy to upgrade, and that it "will remain competitive well into the next century".

Indeed, Burt Richter, the director of the Stanford Linear Accelerator Center (SLAC), points out that the opening of ESRF has not reduced demand for older facilities in Europe. The operating budget for the Stanford Synchrotron Research Laboratory has increased this year from $\$ 17$ million to $\$ 22$ million, keeping the machine on for 40 weeks instead of 30: Richter expects

\section{IMAGE UNAVAILABLE FOR COPYRIGHT REASONS}

Wigglers at work: light simulates particles.

users to grow by 15 per cent this year.

David Moncton, associate director for APS at Argonne, says that his enthusiasm for the new machine is tinged by sadness at the thought that the US Department of Energy may never build a machine like APS again. But Jim Decker, deputy director of the Office of Energy Research at DoE, says: "I don't believe that for a minute." He adds: "People look at the budget climate and say it isn't possible to build anything new. That doesn't mean that in a couple of years the budget climate isn't going to change."

Clearly, however, the APS is the product of a different era. As one senior official of the time puts it: "When the SSC [the Superconducting Super Collider in Texas, since cancelled] got started, every laboratory was to get a toy for itself". Colin Macilwain 